\title{
Estigma e experiência do malungo: a cultura etílica da venda
}

\section{Malungo's stigma and experience: the tavern drinking culture}

\section{Lucas Brunozi Avelar}

RESUMO: O artigo apresenta os resultados parciais de uma pesquisa de doutorado sobre a história das tavernas no Brasil e realiza um esforço inicial de reflexão sobre os contextos de consumo de bebida alcoólica naqueles espaços, bem como nos seus entornos. A partir da crítica de um estereótipo segundo o qual a ingestão alcoólica dos grupos escravizados estava associada ao pecado, ao vício e à doença, investigo suas práticas de beber a partir do conceito de cultura etílica (drinking culture). A taverna foi um dos locais onde estas experiências aconteciam, assim como as senzalas e terreiros. Neste sentido, ela também foi o palco da conformação de identidades e resistências não violentas constituídas pelos africanos diaspóricos.

Palavras-chave: venda-taverna; aguardente; escravos; estigma; ancestralidade.

ABSTRACT: This article presents partial results of a $\mathrm{PhD}$ research on the history of taverns in Brazil and makes an initial effort to reflect about alcohol consumption practices in those spaces as well as in their surroundings. Based on the critic of a stereotype according to which alcohol consumption by enslaved groups was associated with sin, addiction and disease, I investigate their drinking practices using the concept of "drinking culture". The tavern was one of the spaces where these practices took place, as well as the slave quarters and yards. In this sense, taverns were also a kind of other nest to formation of identities and non-violent resistances constituted by diasporic Africans.

Keywords: tavern; distilled alcohol; slaves; stigma; ancestrally.

Recebido em 16 de março de 2020; aprovado em 15 de abril de 2020.

\footnotetext{
${ }^{1}$ Doutorando em História Social na Universidade de São Paulo. Mestre em História Social na FFLCH-USP. Contato: lucas.avelar@usp.br. $\mathrm{O}$ autor agradece aos(às) pareceristas que avaliaram este texto. $\mathrm{O}$ artigo integra uma pesquisa de doutorado intitulada A cultura de taverna da escravidão.
} 
Quando baranco vai na venda Logo dizi tá squentario, Nosso preto vai na venda, Acha copo tá viraro. ${ }^{2}$

\section{Vendas e tavernas em três dicionários}

No dicionário de Raphael Bluteau, de 1721, "taverna" deriva do latim taberna "porque era de Taboado". Porém, segue o verbete, "é de se advertir que naquele tempo Taberna era nome genérico, que se especificava com epithetos das cousas, que nas ditas casas populares, e de taboado, se vendiam; e assim a loja do padeiro se chamava Taberna Pistoria, a de quem contratava em lãa, Tabernalanaria; a em que se vende azeite, Taberna olearia". Neste sentido, segue Bluteau, taverna não era propriamente a casa onde se vendiam vinho e algumas coisas de comer. Para isso, seria necessário acrescentar algum epíteto, Taberna vinaria, por exemplo. Outra acepção da palavra podia ser

loja de algum oficial do povo, amigo dos dous hóspedes, que foram cear na sua casa. Poderas tambem chamar á Taverna, Caupona, ou Popina [...]. Antigamente houve em Roma hum grande edificio, em que se recolhião os soldados estropeados e inválidos; chamava-se este lugar Taberna meritoria. (BLUTEAU, 1721, p. 59)

Bluteau termina o verbete contando que "o Canon 76 do Concilio de Trullo prohibe que no âmbito das Igrejas se abram tavernas. O Canon dos Apóstolos excomunga aos Clérigos, que comem em tavernas, não andando em jornadas". E no terceiro Concílio de Cartagines, cânone 27, foi renovada a proibição. Este mesmo dicionário ainda descreve o sentido de termos e expressões como "cheirar à taverna" ("ter bafo, que cheira a vinho"), "taverneira" ("mulher que tem taverna e a mulher do taverneiro"), "taverneiro" ("o que vende vinho em taverna") e "taverninha" ("pequena taverna"), além de elencar provérbios portugueses relacionados à palavra ("Se não bebo na taverna, folgo nela"; "A tu por tu, como em taverna"; "Meu dinheiro, teu dinheiro, vamos à taverna"; "No Inverno forneira, no Verão taverneira"). Ainda consta "taberna", grafada com a letra $b$ : "Ilha do Egito na Thebaida, onde hoje está a parte Oriental de Sayda. Foi célebre pelos Monges, que nela viviam. Na vida de S.

\footnotetext{
${ }^{2}$ Nei Lopes (1988, p. 171) menciona o Lundu de Pai João como exemplo da influência banta no falar brasileiro.
} 
Pacomio se faz menção de uma vila, que estava na dita ilha, e se chamava Tabernus, e os monges tomaram dela o nome de Tabernniositae" (BLUTEAU, 1728, p. 234).

Em outro dicionário, o de Antonio de Moraes Silva (1789, p. 759), taverna é a "casa onde se vende por miúdo o vinho, azeite, e alguma coisa de comer"; "taverneira é a mulher que tem taverna"; "taverneiro, o que tem taverna"; "taverninha, diminutivo de taverna". E no dicionário Luiz Maria da Silva Pinto de 1832 o termo significa a "casa onde se vende vinho, e de comer pelo miúdo", e taverneiro é o que tem taverna. Eé tudo.

No dicionário de Bluteau, "venda" é "taverna de Estrada. Estalagem do Campo. É tomado do castelhano, Venta, que significa o mesmo" (BLUTEAU, 1721, p. 394; grifo nosso). Outras designações reportam-se ao ato de vender e outra à "tira de pano de cobrir os olhos". No dicionário de Luiz Maria da Silva Pinto "venda" designa "alheação de coisa por certo preço"; "desatar a venda, dissolver, desfazer"; "taverna onde se vende"; "faixa de cobrir os olhos" (SILVA PINTO, 1832; grifo nosso). Consta o termo "vendeira" designando "mulher que vende em taverna" e "vendeiro", "homem que tem venda, ou taverna". E no dicionário de Antonio de Moraes Silva, "venda" é "alheação de cousa por certo preço. Taberna, onde se vende. Faxa, com que se cobre os olhos ao que ia padecer pena de morte. Insígnia com que se representa a justiça. Cegueira" (MORAES SILVA, 1789, p. 838; grifo nosso). "Vendeira" é aquela "mulher que vende pelas praças etc." e "vendeiro", aquele "que vende em taverna". Nos três dicionários consultados, portanto, um dos sentidos de venda é o mesmo de taverna; eram termos correlatos nos séculos XVIII e XIX. A diferença importante é que "venda" era palavra usada para designar o estabelecimento no campo, e, como examino neste artigo a documentação referente aos estabelecimentos rurais, optei por este termo ao longo do texto ${ }^{3}$.

\footnotetext{
${ }^{3}$ A palavra botequim não consta de nenhum dos três dicionários. No de Bluteau, o termo "loja" designa "a oficina, em que se vende qualquer mercância, Taberna, Loja de Livreiro, Taberna Libraria" (BLUTEAU, 1716, p. 175). No de Moraes Silva, é "oficina, ou casa de vender, loja de marcenaria, roupas, livros, sapatos, loja de ourives, barbeiro, tecelão, de bebidas, casa terrea, loja de casa nobre: pateo coberto, que serve de entrada, onde assistem os lacaios, e entram seges" (MORAES SILVA, 1789, p. 235). E no de Silva Pinto, "casa onde se vende, casa terrea, pateo coberto de casas nobres" (SILVA PINTO, 1832). No de Bluteau, "almazem" designa "casa onde se guardam armas, instrumentos de Guerra por mar ou por terra"; "almazem de qualquer provisão e materiais em qualquer quantidade, para exprimir a diversidade das coisas que em diferentes almazens se guardam se acrescentara a palavra Apotheca o nome das cousas, que estão em um almazem" (BLUTEAU, 1728, p. 268). No de Moraes Silva, a acepção se repete acrescentando algumas expressões em sentido aproximado: "provedor de almazens: o que tinha a inspeção dos almazens da Marinha Real, donde saiam as madeiras, massames, virtualhas, boticas, armas para a dita Marinha" (MORAES SILVA, 1789, p. 101). No de Silva Pinto não há definição. Não encontrei referência a nenhuma destas palavras no Vocabulário Brasileiro para servir de complemento aos diccionarios da lingua portugueza, de Braz da Costa Rubim (1853). Para uma diferenciação entre estes estabelecimentos na capitania de Minas Gerais do século XVIII, cf. Chaves (1999).
} 
As vendas e tavernas não foram apenas lugares de se vender bebidas alcoólicas e outras mercadorias. Oálcool também foi consumido do lado de fora do balcão. Seja por conta desta ingestão, seja por abrigar outras atividades vinculadas ou não a ela, formou-se, nesses locais, uma cultura que merece estudo histórico. Os resultados parciais desse estudo são apresentados nas páginas a seguir. Antes, porém, é preciso elucidar que "malungo" é aqui tomado significando tanto a aguardente de cana quanto o "camarada de embarcação", ou ainda o "companheiro da travessia", seja "da vida para a morte branca", seja por outro lado "da viagem de volta para o mundo, preto, dos vivos", isto é, tanto o companheiro de viagem da África para a América quanto a viagem de volta da América para a África (SLENES, 1992, p. $54)$.

\section{Pistas de um estereótipo}

As vendas e tavernas eram locais de comunicação sobre os acontecimentos da vida ordinária e extraordinária nas cidades, nas vilas e nos caminhos. Quando o caxambu iria ser realizado, alguém passava avisando a hora e o local (STEIN, 1990, p. 244). Desde as primeiras décadas do século XVIII, elas abrigavam práticas de ingestão coletiva de álcool pelos grupos escravizados. Luciano Figueiredo (1993, p. 46) fornece pista de que nas tavernas mineiras ocorriam "folguedos e bailes". Hercules Florence (2007, p. 04), no início do século XIX, quando parou para descansar em paragens no caminho até Cubatão, surpreendeu tropeiros dançando, cantando e batendo os pés ao som de violas. Stein (1990), por sua vez, recolheu informação de que após a Abolição os ex-cativos foram até as vendas mais próximas das fazendas onde viviam para dançar o jongo e comemorar a conquista da liberdade. E ainda, segundo Tarcísio José Martins (1995, p. 111), "durante todo o século XIX o batuque sobreviveu nas vendas e festas de gente pobre". Os encontros de taverna serviam, portanto, para negociar, planejar e jogar, e também para beber, dançar e cantar.

Mas do que se tratavam estes batuques, folguedos, bailes, caxambus e jongos praticados nas vendas? Os colonizadores descreveram a festa negra genericamente como "batuque" e diversão "desonesta" porque temiam que fossem "rituais pagãos e atuassem como fermento de desordem social e revoltas", diferentemente dos festejos públicos das congadas, vistas, por outro lado, como "diversão honesta" (DIAS, 2001). Conforme Paulo Dias, já em 1655 na Bahia, a dança negra era associada ao consumo de álcool, assim como à 
desordem e ao "sensualismo" na crônica colonial de inspiração católica. A importância da pinga atravessou os séculos e faz parte das religiões de matriz africana no presente. Segundo Luciano Gallet (1934, p. 60-74), as danças negras implantadas no Brasil eram "danças de conjunto" como o jongo (Rio de Janeiro), o samba (Pernambuco), o coco de zambe (Rio Grande do Norte), nas quais "se formam de grandes rodas de homens e mulheres, que cantam em coro, batem as mãos em tempo, e dançam com o corpo, sem sair do lugar. No centro da roda, um dançarino, às vezes dois, evoluem em danças saracoteadas, de grande agilidade, e de execução difícil". O "cantador" improvisa a estrofe, o coro responde, e "estas danças prolongam-se dia e noite; desde que circule a 'pinga' e que os ânimos se mantenham exaltados". E o jongo era a dança predileta "por causa da grande quantidade de pessoas que nela tomavam parte, podendo prolongar-se indefinidamente", com a mulher ou o homem dançando no meio da roda, embalados "com as baterias, o sapateio, o canto geral e o parati que circula horas a fio".

Ao estudar o samba rural paulista na primeira metade do século 20, Mário de Andrade (1937, p. 41) igualmente observou a pinga circulando: "eis justamente uma das atribuições do dono-do-samba. Ele é que de garrafa e copinho, vai um a um dando pinga. Os homens não recusam nunca. As mulheres vi algumas recusar". Era assim que o "dono" mantinha "verdadeira autoridade sobre os seus comandados", controlando a circulação da substância - se a pinga fosse proibida antes da realização do bailado, "ninguém que se lembrasse de desobedecer". Havia uma cultura etílica formada pelos grupos escravizados que rememorou uma herança centro-africana e foi abrigada nas senzalas, nos terreiros e nas tavernas, chegando, por isso, até os nossos dias.

A ideologia racista por outro lado procurou desautorizar a festa negra acusando seus participantes de "cachaceiros", mas o álcool destilado cumpriu funções outras que não a da mera embriaguez. O consumo de bebida alcoólica pelos africanos fora descrito como pecado ao menos desde o início do século XVIII, quando o jesuíta italiano Jorge Benci compreendeu a ebriedade escrava como um problema porque era realizada pelos "filhos de Cam", os portadores da maldição de Noé inclinados ao vício. Por isso, deveriam ser escravizados a fim de evitar que se entregassem ao álcool, às brigas e às "danças desonestas" (BENCl, 1977, p. 192-193). A seus olhos, a escravização, portanto, era uma forma de corrigir a inclinação que os africanos tinham para a embriaguez por terem sido amaldiçoados. 
Se, nas palavras do religioso, a embriaguez escrava era um pecado, na pena dos liberais o tema avançou na construção do estereótipo racial. Ernst Ebel, viajando pelo Rio de Janeiro em 1824, refletiu sobre a "natureza do negro em geral" e afirmou que era inútil tratálos bem. Era necessário mantê-los sobre severo controle pois os homens eram inclinados à bebida, ao roubo e à preguiça, e, quanto às mulheres, era difícil moderar seu instinto (EBEL, 1972, p. 45). Espécie de última palavra sobre o racismo naquele início de século, esse discurso estava alinhado à filosofia liberal interessada em explicar por que a noção de direitos não deveria ser estendida a todos os setores da sociedade. Manter a escravidão para evitar a preguiça, estimular o casamento para evitar a incontinência sexual e realizar punição severa para acabar com a embriaguez tornaram-se imperativos porque, segundo essa ideologia, os africanos eram incapazes de autocontrole e, portanto, precisavam de tutela.

Os negros seriam incapazes até de se lembrar do passado e de planejar o futuro. Ao descrever as senzalas que observou, o viajante Ribeyrolles (1980, p. 41) refere-se a elas como sendo "antros, onde reinam às vezes as distrações e prazeres bestiais da embriaguez, em que jamais se fala do passado, porque é a dor, nem do futuro, porque está cerrado". A senzala, então, seria o espaço dominado pelo prazer bestial da embriaguez, que, por sua vez, seria o momento de negação completa ("jamais") tanto do trabalho de memória marcado pelo sofrimento quanto do planejamento do porvir.

Este estereótipo atravessou o século, passando de uma noção assentada no pecado e no vício até chegar à vinculação da embriaguez com a doença. Com a ingestão de bebida alcoólica, o negro teve sua imagem reiteradamente estigmatizada como sendo prova de sua inferioridade. Ao descrever as "características sociais desse negro cativo", Louis Couty (1988, p. 95-96) reforçou a acusação de preguiçoso e o comparou às crianças: "a maior parte dos negros adultos apresenta muitas das características das crianças de nossas sociedades civilizadas. Como as crianças, eles têm os sentidos inferiores, especialmente o paladar e a audição, relativamente desenvolvidos". Com relação ao paladar,

o negro gosta do tabaco, do arroz, do milho bem tostado, adora os doces, a rapadura, mas, acima de tudo, gosta da cachaça ou aguardente de cana impura fabricada no País. Para obter cachaça, rouba: para obter cachaça, fugirá durante a noite; e, sacrificando-se mais por esta paixão que pela própria liberdade, poderá até trabalhar aos domingos. (COUTY, 1988, p. 95-96) 
Por isso, um escravo "cujo campo particular esteja cultivado, pode ser simplesmente um beberrão mais determinado. Apesar de toda a vigilância, de todas as proibições, de todos os castigos, é frequente verem-se escravos bêbados nas fazendas, e, segundo consenso geral, a bebedeira é o seu maior defeito" (COUTY, 1988, p. 95-96). O estigma do álcool reiterado nessas ideias, agora enquanto expressão da infantilidade do negro e da incapacidade de se autocontrolar, só seria questionado décadas depois pelo médico Juliano Moreira, no contexto da expansão do eugenismo no Brasil.

Em todo caso, esse breve panorama geral do conjunto de elaborações que atenderam aos esforços de objetificação do negro pretende indicar a variação diacrônica do estigma que integrou o racismo estruturador de nossa formação histórica a partir das décadas de 1830 e 1840. A desumanização, escorada nessas descrições, contribuiu para a naturalização do uso problemático do álcool pelos cativos e seus descendentes livres, na medida em que explicou estes usos como signos de pecado, vício e doença. De modo geral, este conjunto compôs o esforço de inferiorização das mulheres e dos homens arrancados da África. Nas palavras de Fanon (1956), "não é possível subjugar homens sem logicamente os inferiorizar de um lado a outro. E o racismo não é mais do que a explicação emocional, afetiva, algumas vezes intelectual, desta inferiorização". O estigma do álcool integrou a racialização de pessoas negras no Brasil, generalizando a explicação do uso da substância para todos os grupos. Nas linhas a seguir, pretendo avançar na compreensão histórica do consumo de álcool pelos grupos escravizados no Brasil do século XIX a partir de uma perspectiva antirracista.

\section{A cultura etílica dos grupos escravizados: apontamentos iniciais}

Thomas Wilson (2005) define "drinking culture" como o conjunto de práticas e significados relacionados ao consumo do álcool. A expressão procura investigar se os lugares, os espaços e as práticas de beber cumprem alguma função na construção de identidades políticas e sociais. A premissa é que a ingestão de álcool é uma prática-chave na expressão da identidade grupal, um elemento na construção e disseminação da cultura de um grupo. $O$ ato de beber está intrincado, em algum nível, em todo tipo de cultura e implica valores, comportamentos, ideologias e a história das sociedades. Reportando-se a Dwight Heat, Wilson (2005, p. 03-05) afirma: "com drinking cultures nós estamos examinando simultaneamente o consumo de commodities e os comportamentos de integração e 
diferenciação social e cultural". Neste sentido, o álcool é visto tanto como uma mercadoria quanto como um elemento em diferencial regime de valor na história de grupos étnicos ou nacionais. Como os antropólogos encontraram evidências de que o consumo de álcool é um aspecto celebrado e importante de muitas sociedades, o estudo de seus usos pode fornecer uma janela útil para a observação de diferentes tipos de crenças e atitudes. Os espaços de beber seriam locais onde sentidos são produzidos e redes de amizade, trabalho, negócios e políticas se formam e engendram processos de diferenciação. Drinking culture é um aspecto da cultura, parte de uma conjuntura maior de significados, maiores campos de afiliação, identificação e ação4 .

O uso da bebida alcoólica para invocar divindades fora mobilizado pelos grupos escravizados desde o século XVII, associando a pinga a São Benedito (ALENCASTRO, 2000, p. 165).

\author{
Meu São Benedito \\ É santo de preto; \\ Ele bebe garapa, \\ Ele ronca no peito!
}

Mary Karasch (2000, p. 435), por sua vez, informa que "para aliviar o fardo da escravidão, muitos escravos entregavam-se à bebida e a fumar diamba (maconha)". Carl Schlichthorst é um dos viajantes citados pela autora que comentou sobre a capacidade de beber dos negros, mas observou também que era raro vê-los bêbados pelas ruas. Karasch sugere que o uso de bebidas alcoólicas era comum entre mulheres e homens escravizados por diferentes razões: pelo baixo preço da cachaça; por ser gênero básico da dieta dos cativos; por ser complemento alimentar porque "não tinham meios para obter alimentos mais nutritivos"; "suspeitava-se também que ela tinha lugar muito importante nos rituais

\footnotetext{
${ }^{4}$ Beber é concebido como um ato social que marca fronteiras pessoais e grupais, uma prática de inclusão e exclusão. E o álcool é um elemento na construção social: "beber é uma prática chave na construção social do mundo como ele é e como ele poderia ser". Assim como o alimento, o álcool é um elemento de identificação e diferenciação; o que, como, onde e quando bebemos permite fazer julgamentos sobre os outros e suas identidades. Neste sentido, o autor resumiu a perspectiva com a máxima: "Diga-me o que você bebe, e eu te digo quem você é" (WILSON, 2005, p. 13).
} 
religiosos, nos quais eram feitas oferendas de bebida alcoólica aos espíritos"; e, por fim, "a bebida era também uma parte importante da vida social dos escravos e boa parte dela era socialmente aceitável para os escravos, se não para os senhores" (KARASCH, 2000, p. 437).

A historiadora ainda faz referência a três casos que informam sobre o uso abusivo da bebida: o de uma africana livre que bebia e, por isso, fora afastada do filho; o de um sapateiro mulato que foi vendido porque se embriagava apesar de ser "mui consciencioso", segundo seu senhor; o de anúncios de fugas relatando que “beber demais era um dos 'vícios' de muitos fugitivos, nas palavras de seus donos". Estes casos são classificados como expressões da "resistência não violenta" à escravidão, caracterizada por "rituais espirituais para controlar os senhores, diminuição do ritmo de trabalho e doenças fingidas para evitar o trabalho duro, apatia geral ou fatalismo, insultos e obscenidades e comportamentos autodestrutivos, como o excesso de bebida e abuso da maconha" (KARASCH, 2000, p. 437). Karasch cita o caso de escravos que mataram seus donos e "em uma espécie de ritual religioso" beberam o sangue deles.

Portanto, uma série de fatores explica o disseminado uso do destilado de cana pelos grupos escravizados. A despeito do fato de a bebida ser socialmente aceitável entre os senhores, Mário Souto Maior alega que eles foram responsáveis pela disseminação do "vício da embriaguez entre os negros". A consequência disso foi que os escravos sofreram castigos no tronco, do carro ou "surra-de-tira-mandinga-de-negro" por abusar da cachaça ou furtar aguardente. O folclorista resume a situação da seguinte maneira: "o que os escravos buscavam na cachaça era o remédio para os castigos recebidos e para as injustiças sofridas. Depois de um longo dia de trabalho sob ordens de um feitor às vezes desumano, eles se viam com o direito de afogar suas mágoas, suas saudades africanas" (MAIOR, 1985, p. 37-38).

A oferta de álcool destilado de forma sistemática por conta da expansão capitalista europeia a partir do século XVI fez parte do esforço de dominação colonial mobilizado pelas potências metropolitanas. Embriagar os negociantes dos enclaves coloniais e fazer trocas vantajosas para os comerciantes do Velho Mundo é prática conhecida e bastante documentada (WILLIAMS, 2012). E, por ser um psicoativo, o álcool é uma mercadoria com alto potencial de permutabilidade. Ele poderia ser utilizado em diferentes esferas da vida social. Mas, acima de tudo, com o fim de aumentar a intensidade da exploração do trabalho e com isso garantir maior expropriação de excedente econômico, o estímulo ao consumo de álcool destilado se espalhou pelos locais em que os europeus aportaram. Os padrões de 
consumo problemático nas colônias explicam-se, ademais, pela tensão provocada pelo trabalho coercitivo em uma sociedade rigidamente marcada por hierarquias de classe, raça, gênero, religião e identidade étnica. A incerteza de chegar a um local absolutamente desconhecido, que se acreditava até mesmo ser outro mundo, pode ser incluída como força que explica a demanda pela bebida alcoólica. De modo geral, tomados em conjunto, esses fatores ajudam a nos aproximar da compreensão do problema de saúde pública no que se refere ao uso endêmico de álcool pelas classes menos favorecidas, sobretudo as do campo, onde escasseavam as atividades para além da casa-trabalho.

Em paralelo, formou-se uma cultura etílica como parte da resistência não violenta à escravidão. Nas páginas a seguir, vou me ater a este outro lado da questão: o da presença da substância na religiosidade africana enquanto elemento que fez parte da reconstrução de uma cultura etílica de matriz centro-africana no Brasil.

Estudando o caxambu de terreiro da cidade de Vassouras, a historiadora Camilla Agostini (2002, p. 90-92) concluiu que aqueles encontros serviram "como uma prática associativa importante na organização social de africanos e afro-brasileiros no cativeiro, através da qual querelas do cotidiano podiam ser resolvidas em desafios de habilidade com a palavra". Este "legado compartilhado por afro-brasileiros" contribuiu para resolver querelas do cotidiano sem o uso da violência e do crime e para criar um senso de associação e camaradagem. Ao examinar os aspectos da linguagem particular dos grupos escravizados, Agostini sugere que a prática "pode ter servido como veículo na negociação de africanidades, e como parâmetro na construção de novas identidades, como a do próprio 'africano', ainda no 'tempo do cativeiro'" (ACOSTINI, 2002, p. 90). Reportando-se a Paulo Dias, a historiadora destaca que a referência aos antepassados aparecia também no candombe mineiro do século $X X$, e um dos jongueiros entrevistados por ela sublinhou que, em meio às libações de aguardente nos encontros de jongo, faziam-se presentes reis, rainhas e o povo quando "o espírito suga ali, bebe, ajuda, dança, protege e faz o que a gente quer" (AGOSTINI, 2002, p. 106) $)^{5}$. Nas palavras de Agostini (2002, p. 107), "a referência aos ancestrais poderia, assim, ter servido à determinada coletividade como uma referência de um passado-ancestralidade comum, ou à referência a um passado que passava a ser inventado e compartilhado". Na linguagem do jongo-caxambu haveria uma "gramática profunda" que teria fundamentado a

\footnotetext{
${ }^{5}$ Em tempo, caxambu era o encontro em torno dos toques dos tambores, bem como as danças nestas ocasiões; jongo por sua vez eram os "pontos", isto é, os versos cantados. Cf. Agostini (2007, p. 01).
} 
negociação das diferenças entre os grupos escravizados. Esta linguagem teria servido como veículo para negociação de diferenças, bem como para conferir unidade entre os participantes (SLENES, 1992). As ocasiões do caxambu foram, assim, compreendidas como um "espaço no qual centro-africanos teriam a chance de reconhecer práticas culturais comuns", além de instituições fundamentais para a constituição de comunidades escravas, seja pela coesão social "em torno de uma prática enraizada num legado africano reconhecido entre cativos de 'diferentes nações", ou pelos "conflitos inerentes à nova formação social que passava a se estabelecer no cativeiro brasileiro, através de uma linguagem própria aos negros africanos e transmitida aos seus descendentes" (ACOSTINI, 2002, p. 111). Agostini observa ainda que "talvez algumas doses de aguardente e uma 'assuntada' no local" fossem preâmbulos para os cantadores exibirem suas habilidades e instigarem uma disputa.

Estudando o material coletado por Stanley Stein referente ao jongo e ao caxambu de Vassouras, Robert Slenes fornece pistas sobre o significado da pinga usada naquelas ocasiões. Em uma disputa entre mestres jongueiros, um deles encheu a boca com a bebida e cuspiu-a nos olhos do filho de um dos seus rivais, que "'cegou na hora' [desmaiou]". Na mesma hora, outro jongueiro correu ao rio, encheu uma caneca d'água e jogou na fogueira; pegou a cinza que se formou e soprou-a nos olhos do rapaz, "que 'acordou na hora". "Por que a pinga cegou?' Perguntou alguém. 'Porque estava temperada'. 'Com o quê?' 'Palavra. Só palavra. Não precisa de mais nada"' (SLENES, 2007, p. 136-138). Com relação a estas propriedades mágicas da pinga, Slenes as associa ao culto de José Cabinda em São Roque, que também usava o líquido "para facilitar a posse espiritual, provavelmente conforme preceitos nominalistas que associavam (em kikongo) nsámba, o vinho de palmeira mais prezado para libações em ocasiões formais, com outro nsámba, 'oração', e palavras relacionadas significando 'ora, invocar'".

Enquanto facilitador da posse espiritual, o álcool era então associado à oração, à invocação. O jato de pinga "temperado com palavras" em direção aos olhos da vítima "é um verdadeiro ‘nzòngo mya `nnua, um 'tiro-combate com a boca'”. Interessado no significado da estória, Slenes a compreende como expressão da "visão nominalista do poder das palavras sobre as coisas", o que, portanto, reforçava "a ideia de que falantes de kikongo no Brasil faziam ligações semelhantes entre as palavras agrupadas em torno dos vários sentidos barulhentos de kúmba" (SLENES, 2007, p. 139). Os "pressupostos nominalistas" consideravam que "as palavras revelavam a ontologia das coisas" e isto levou os kongo a "associar as asas dos 
pássaros ou a de insetos, em movimento rápido, com 'os espíritos (mpeve) [,] porque [...] asas (maveve) movimentam o ar (vevila, 'abanar')', e com a 'adivinhação, um assunto de revelação espiritual (mu mpeve)". Todavia, “o zumbido das asas de abelhas' (kúmbu) aponta independentemente para o mundo espiritual".

Mas a bebida alcoólica participou também de outros cultos de matriz centro-africana. Estudando os "fundamentos do consenso nas senzalas" do Sudeste fluminense e paulista do século XIX, o mesmo Robert Slenes localizou um ritual ocorrido em 1854 na vila de São Roque, na província de São Paulo, em que se mencionava o uso do "malavo". Slenes, neste caso, estava interessado em compreender a reconstrução dos cultos kimpasi na região. Estes cultos floresceram na África Central em meados dos séculos XVII e XIX, em ambos os casos em resposta à desagregação social causada pelo colonialismo, primeiro o lusitano, segundo o belga. Kimpasi eram sociedades secretas cultuadas na crença de que resolveriam crises coletivas (ecológicas, guerras civis, razias), por meio da "devoção a pedras de formas estranhas, geralmente encontradas em cursos de água e consideradas nkisi-nsi, isto é, 'objetos sagrados da terra', que manifestavam-corporificavam espíritos bisimbi"; da utilização de uma "língua secreta" por parte dos membros dos cultos; de reuniões em clareiras na profundidade da floresta; da inclusão de mulheres e homens como adeptos e novos membros; da “iniciação através de uma cerimônia de morte ritual seguida de renascimento, com o novo membro, em transe, incorporando um espírito-guia individual, cujo nome e identidade carregava o resto da vida" (SLENES, 2006, p. 288-289). Ao examinar o movimento religioso de São Roque, Slenes decifrou frases que se referiam ao consumo do vinho de palma, "malavo", como sendo uma das pistas de que se travava de um culto relacionado ao Kimpasi. As outras pistas eram o uso de estatuetas (de Santo Antônio), o diálogo com uma ponta de chifre, o canto em uma "linguagem ininteligível", reuniões perto do mato, homens e mulheres perto do altar, dentre outras. O "culto de São Roque", ademais, preocupou as autoridades policiais, que viram nele a possibilidade de conter uma dimensão política e não apenas religiosa. O líder do ritual, o "preto forro" José Cabinda exigia o fermentado para ingestão durante a cerimônia. Era exigência fundamental. Mas por quê? O que significava a exigência do psicoativo nestas ocasiões?

Ao longo da República, o processo de branqueamento da cultura etílica expulsou a festa negra das vendas, mas o consumo de álcool durante as libações permaneceu. Carolina dos Santos Bezerra-Perez, ao estudar o jongo de Guaratinguetá do início do século XXI, é 
informada por seus entrevistados de que, após serem apurados pelo fogo, "o tambu e o candongueiro estão prontos para também apreciarem a aguardente. Os tambores são muito mais que meros instrumentos, estão vivos, pois possuem nomes, características e sentimentos". Para a abertura da festa era preciso "saravar os tambores com aguardente, ou simplesmente passar a cachaça no tambu". Bezerra-Perez cita um trecho da entrevista com Dona Mazé, que afirma: "O tambu também é realmente um instrumento muito respeitado no Jongo. Porque ele recebe um nome, também significa como se fosse um Orixá pra gente ali. Então, ele tem que ser saravado, ele tem que ser respeitado, ele tem que ser cumprimentado na roda de jongo, porque ele é um respeito". Conforme esta autora, o ato de saravar está relacionado à reverência, à louvação e à exaltação dos tambores, "é a própria oblação, a ação de se oferecer, saudar, exaltar a Deus, aos deuses, santos, jongueiros velhos e espíritos. A oblação é também o oferecimento da bebida que, em contexto ritual, sacralizase". Segue afirmando que

O Tambu e o candongueiro são a ancestralidade, os jongueiros velhos. Desta forma existe um respeito muito grande para se iniciar uma roda de jongo. A aguardente, ou melhor, marrafa, como é chamada pela Dona Mazé, é passada às suas mãos na abertura da roda de jongo. Ao recebê-la, asperge os tambores com a aguardente. Destarte, a aguardente traz a purificação, a ardência do fogo visando à limpeza e à purificação das pessoas, dos terreiros e dos objetos. Depois de beberem, Dona Mazé sai andando e cantando pelo terreiro espargindo as bênçãos em todas as pessoas que estão na roda, no círculo, e pelo terreiro. Vai saravando e molhando a mão na cachaça e borrifa também na fogueira, distribuindo as suas bênçãos por todo o espaço onde se desenvolverá a performance, 0 ritual: "A fogueira é pra esquentar o tambor e pra dar mais luz pros espíritos que vem nos ajudar, sabe, porque numa roda de jongo parece muitos jongueiros, sabe, e aqueles jongueiros vêm com força, com luz pra nos orientar, pra nos dar força, pra nos guardar. Precisamos jogar cachaça, precisamos passar a cachaça no Tambu saravando jongueiros velhos, nunca se faz nada, abre uma roda de jongo sem saravar os jongueiros velhos". (BEZERRA-PEREZ, 2012, p. 199-200).

\section{Outros contextos}

Há ainda outras referências da presença de bebidas alcoólicas ou não na religiosidade dos grupos escravizados e afro-brasileiros. Estudando resistência escrava, Maria Helena Machado (2010, p. 98-100) informa que os feiticeiros exerciam o papel de organizar "uma seita religiosa baseada em práticas mágicas e voltada para a obtenção da liberdade". Dentre 
outras atividades, eles distribuíam entre os escravos “'bebida preparada com raízes', considerada como possuidora de poderes mágicos que os tornaria invencíveis e incitando-os a resistirem ao senhor".

Por sua vez, para fazer a diferenciação entre o "nosso Demônio" católico e os "deuses do firmamento negro", Câmara Cascudo ressalva que

\begin{abstract}
Exu é um portador, mensageiro, Hermes africano. Exige, decorrentemente, seu salário ritual, o seu despacho integral; azeite-dedendê, bode, cachaça, fumo. Lembrarem-no nas segundas-feiras. Nada mais. Esquecido, vingar-se-á pondo sua influência no sentido contrário da pretensão pleiteada. O lógico será satisfazê-lo com os alimentos preferidos; come tudo, informa Donald Pierson, e gritar-lhe a saudação privativa: Larôiê! Exu não tem a maldade congênita, medilar, alheia à provocação inconsciente do olvido devoto. Sua suscetibilidade, caráter irascível, turbulento, inquieto, vingativo, são invariavelmente reações, réplicas, represálias. Satanás não guarda a casa de ninguém. Exu, repleto e tranquilo, é guardião incomparável. (CASCUDO, 2001, p. 109)
\end{abstract}

Orixá da comunicação entre os mundos, que requisita a cachaça como veículo de contato, Exu é o único a quem o destilado constitui uma oferenda (POEL, 2013). Nome genérico associado às forças da natureza que podem se tornar presentes através da possessão, os orixás estão ligados a elementos da natureza, à psicologia da pessoa e aos antepassados. As religiões de possessão dos cultos afro-brasileiros evocam essas divindades, ocasiões em que precisamente o orixá Exu e os "inquices"6-ambos mensageiros - demandam o álcool destilado.

Em todo caso, a aguardente não era apenas ingerida e ofertada, mas também era e é usada para desenhar o "ponto riscado", que é um sinal ritual desenhado também com pemba (giz) ou pólvora, para chamar as entidades sobrenaturais, principalmente na umbanda e na pajelança; "ao invocar exus, orixás, pretos velhos, caboclos ou encantados, os pontos riscados e os pontos cantados complementam-se" (POEL, 2013). O ponto riscado de Cristo, grosso modo, equivale ao sinal da cruz no cristianismo. Esses pontos representam as entidades e também podem ser pintados em paredes, azulejos, tábuas ou qualquer outra superfície. Portanto, a bebida alcoólica não era apenas ingerida: ela molhava os instrumentos, era jogada no chão e usada para fazer as marcações rituais no espaço (POEL, 2013).

\footnotetext{
${ }^{6}$ Em duas palavras, inquice era o receptáculo e a divindade encantada bantu ligada às forças da natureza.
} 
Cascudo acrescenta que o espírito chamado "Zumbi", que os africanos de Angola acreditavam estar sempre por perto deles, é outra figura que demandava cachaça e fumo. Entre as características deste Zumbi, Cascudo coleta a seguinte:

Capelo e Ivens ${ }^{7}$, referindo-se aos negros da região do Dombe Grande, dizem: '...vê-se frequentemente ao beberem aguardente, entornar no chão uma pequena parte, a fim de contentarem, segundo parece, o Zumbi ou n'zumbi (Alma do outro mundo), por quem sempre julgam estar cercados, e mas ou menos em relação, esfregando em seguida a testa e o peito como remate à cerimônia'. No Brasil costumam também as negras africanas, quando comem ou bebem água ou aguardente, deitarem as primeiras porções no chão e a esse ato, quando se lhes pergunta, dizem que é para o santo, que se acha perto delas. Entre algumas crioulas dá-se o mesmo fato e dizem que é para S. Cosme e S. Damião, dois santos da predileção das escravas pretas, que desejam as suas alforrias por intervenção dos mesmos santos. (CASCUDO, 2001, p. 116)

\section{Ancestralidade alcoólica}

A ingestão coletiva de bebida alcoólica pelos africanos diaspóricos e seus descendentes talvez possa ter contribuído para conservar e reelaborar o que Michael Pollak (1989) compreendeu como "memória subterrânea", que se oporia à "memória oficial". A memória subterrânea é transmitida dentro da família, em associações e redes de sociabilidade afetiva e ou política, sendo composta por lembranças proibidas, indizíveis ou vergonhosas, "zelosamente guardadas em estruturas de comunicação informais [qu]e passam despercebidas pela sociedade englobante" (POLLAK, 1989, p. 8). Discursos, silêncios, alusões e metáforas existentes nestas lembranças são moldadas "pela angústia de não encontrar uma escuta, de ser punido por aquilo que se diz, ou, ao menos, de se expor a malentendidos" (POLLAK, 1989, p. 8).

O álcool era um forte componente médico e espiritual na África Centro-Ocidental. Os africanos que aportaram na América provinham de sociedades com profundo respeito espiritual à substância. Para os congoleses, o malavu era requerido em ocasiões rituais e cerimoniais em honra aos ancestrais. O missionário Karl Laman, que visitou os congoleses no fim do século XIX, observou "casas especiais para a guarda segura do nkisi, ídolos e imagens

\footnotetext{
${ }^{7}$ Neste trecho, Câmara Cascudo refere-se ao relato da viagem à África Central e Ocidental, realizada por Hermenegildo Capelo e Roberto Ivens e publicada no livro De benguela às terras de laca, com primeira edição em 1881.
} 
ancestrais. Também encontramos pequenas casas ancestrais bem construídas nas quais há uma caneca, dentro da qual alguém derrama vinho de palma que é sacrificado aos ancestrais" (SMITH, 2005, p. 101). À medida que a morte significava a transição para o mundo dos espíritos, o status do álcool nos ritos funerais expressava seu valor espiritual enquanto oferta que pretendia assegurar a passagem bem-sucedida do morto. Ademais, oferecer álcool também garantia que "o morto iria prestar assistência e prosperidade à família e à comunidade deixada para trás" (SMITH, 2005, p. 101). A maioria dos africanos partilhava crenças semelhantes a respeito da importância espiritual do álcool, ao qual atribuíam a capacidade de facilitar a comunicação com o mundo espiritual por meio de libações e oferendas. A oferta da substância manifestava reverência aos ancestrais e às deidades (SMITH, 2005, p. 97-102).

Os Kongo ainda tinham o hábito de queimar o morto em lugares escolhidos nas montanhas e levar vinho e alimento a eles, e os Imbangala faziam "uso extensivo do vinho de palma em seus rituais derramando-o sobre os túmulos de seus ancestrais na tentativa de entrar em contato com o morto" (SMITH, 2005, p. 100). Na África Centro-Ocidental, os Kongo eram conhecidos desde o século XVII por serem povos que enterravam seus mortos nas montanhas em belos lugares e levavam vinho e comida para eles. Conforme o relato de Karl Laman, imediatamente após o enterro, o alimento era trazido para que pudesse comer 0 falecido, que havia se transformado em espírito nkuyu, e pela mesma razão o vinho de palma era derramado sobre o túmulo. Em conexão a isto, as pessoas que estavam em luto (enlutados, pranteadores, no original "mourners") "também bebiam o vinho de palma no túmulo onde o falecido foi concebido ("conceived") para viver" (LAMAN, 1953, p. 67). Vinho de palma, carne e outros alimentos eram postos no túmulo para assegurar bons sonhos aos sobreviventes e, para o falecido, ajuda e benção. O morto era frequentemente enterrado na casa onde o vinho de palma era bebido, assim ele não poderia ser esquecido. Conforme Laman (1953, p. 67), "uma cabaça inteira de vinho era derramada sobre o túmulo" e, se o falecido fosse uma pessoa bem conhecida e honrada, sua sepultura seria bem cuidada, a grama retirada e homenagens seriam feitas: "a comida é colocada nas sepulturas e o vinho de palma é derramado em canecas colocadas para o propósito". A comida e o vinho de palma eram então colocados regularmente por longo período, com orações e bênçãos ao falecido.

Os Imbangala, por sua vez, faziam extensivo uso do vinho de palma nos seus rituais e derramavam vinho sobre os túmulos dos seus ancestrais na tentativa de entrar em contato 
com os mortos. No funeral Ouidah, relatos informam a prática de distribuição de álcool por toda a noite, junto de danças e cantos. Os Akan colocavam alimentos e bebidas nos túmulos dos mortos na crença de que eles viviam naqueles materiais e, então, potes de água e vinho de palma eram constantemente renovados. $\mathrm{Na}$ Costa do Ouro, quando os cadáveres eram deixados dentro dos túmulos, as pessoas que cuidavam do funeral bebiam vinho de palma em chifres de bois, e o que não conseguiam beber era derramado sobre a sepultura do amigo morto, que podia assim ter sua parte da bebida. Os Igbos também derramavam álcool nos cadáveres antes do enterro, e quantidades ilimitadas de vinho de palma eram consumidas durante a festa do "segundo enterro". Eles ofereciam álcool aos ancestrais nas cerimônias funerárias para assegurar que os espíritos ancestrais iriam dar boas vindas ao que recentemente partiu, e depois do funeral os parentes vivos faziam ofertas de álcool para seus mortos. O avanço colonial provocou a substituição do vinho de palma pelo álcool destilado (SLENES, 1992; THORNTON, 1992; SMITH, 2005).

Entretanto, este papel de abrir canais de comunicação com o mundo ancestral nos enterros, de certo modo, foi conservado. O uso generalizado do álcool refletiu a necessidade de reunir a comunidade durante esse ansiado período de liminaridade espiritual. A transição para a morte marcava um período de tensão comunitária, quando os mundos terrestres e espirituais estavam próximos. Os efeitos do álcool nos indivíduos, nos ancestrais e nas deidades podem ter produzido uma percepção de ordem e controle que ajudou a estabilizar a comunidade durante essa fase incerta e imprevisível. Estas crenças em comum, partilhadas inclusive de certo modo pelos europeus, pode ter contribuído para unificar africanos de diferentes "nações" nas plantations do Novo Mundo. Se este for o caso, o uso sagrado do álcool contribuiu para a construção de novos costumes de beber afro-orientados, baseados em crenças compartilhadas. E as tradições de consumo do álcool fermentado na África Central podem ter colaborado para o desenvolvimento da habilidade de incorporar a nova variedade de álcool (o destilado) em uma forma tradicional de espiritualidade, que contribuiu para a adaptação cultural dos africanos na mudança de ambiente (SMITH, 2005).

\section{Outros frequentadores}

A cultura etílica da venda não foi partilhada apenas por africanos e seus descendentes. Desde o século XVIII, a taverna era frequentada por diversas categorias sociais 
- todo mundo bebia na venda. E essa variedade de frequentadores fica expressa na produção folclórica, que inclui poemas e lodaças. Dois poemas exemplificam esta característica (BRASIL, 1925, p. 201-202).

\section{O beber}

Quem mais pouco bebe

É o sacristão,

Se chega na venda

Empenha o botão.

Quem mais pouco bebe

É seu vigário,

Se chega na venda

Empenha o rosário.

Quem mais pouco bebe

É a moça bonita,

Se chega na venda

Empenha uma fita.

Quem mais pouco bebe

É a moça solteira,

Se chega na venda

Empenha a pulseira.

Quem mais pouco bebe É a mulher casada,

Ela chega na venda,

Está relaxada.

Quem mais pouco bebe É a mulherviúva,

Ela chega na venda

E empenha é a luva.

Quem mais pouco bebe É a moça branca,

Se chega na venda

Empenha a tamanca.

Quem mais pouco bebe

É a mulher do papudo,

Se chega na venda

Ela bebe de tudo.

A expressão "mais pouco bebe" significa bebe pouco. Ao listar em rimas as pessoas que iam beber um pouco na venda é possível começar a medir a dimensão da variedade de 
categorias sociais que frequentavam aqueles espaços. Já o segundo poema foi mencionado no Dicionário da religiosidade popular, organizado por Francisco Vander Poel (2013), no qual o verbete "venda" é descrito como "casa popular de comércio no interior; o mesmo que boteco e boliche (RS)". Conforme Poel (2013), "antigamente, a venda era o ponto de encontro" e, citando o poema "ABC da Venda", anotado por Alfredo do Vale Cabral, "mostra que, mesmo na venda, vida e religião são inseparáveis":

As gentes que vimos De todas as classes: Entram com disfarces Na venda.

Beatas também, Sempre confessadas, Vão embriagadas $\mathrm{Na}$ venda.

Caixeiros e amos Por contas erradas Jogam às murradas Na venda.

Doutores de banca, E outros "charás" Formam "provarás" Na venda.

Escrivães e escreventes Com seus ajudantes São firmes, constantes $\mathrm{Na}$ venda.

Frades infinitos E moços donatos Alimpam sapatos Na venda.

Ganhadores sós Não podem beber O que há a vender Na venda.

Homens e mulheres Velhos e meninos Repicam os sinos Na venda.

Jaquetas, casacas, 
Timões e capotes

Só não bebem em potes

Na venda.

Meleiros chapados

São os sujeitinhos

Que beijam os bentinhos

Na venda.

Não fiquem de parte

Os procuradores

Que também fazem favores

Na venda.

Oradores vimos

Que finda a função

Repetem o sermão

Na venda.

Piratas e clérigos

Frades minoristas

Também são coristas

Na venda.

Quartéis e conventos,

Lojas e escritórios,

Têm seus purgatórios

$\mathrm{Na}$ venda.

Roceiros, feitores

E tudo dos matos,

São mais do que ratos

Na venda.

Soldados então,

Só levam a fama:

Todos fazem lama

Na venda.

Tolos e sabidos

'Té os inocentes

Nascem-lhes os dentes

$\mathrm{Na}$ venda.

Viúvos, casados,

Solteiros e tudo

Ninguém fica mudo

Na venda.

Xixib.u.a.

Que afeta de sério

Também fica ébrio

Na venda. 


\section{Zumbi, lobisomem \\ E outros fadários \\ Ofrecem rosários \\ Na venda. \\ Só o pobre "til" \\ Por ser pequenino \\ Fica num cantinho \\ Na venda.}

Todo mundo ia beber um pouco ou muito na venda, e, assim, ela se tornou o lugar de encontro de pessoas de diferentes classes, origens, religiões, cores, gêneros, idades, tamanhos, estados civis, tipos de vestimenta, graus de escolarização, resistências ao álcool etc. Fosse para beber em ritual, para apenas um trago ou por outras razões, o fato é que a venda foi o espaço público onde os oprimidos se expressavam, diferentemente da imprensa e do Parlamento.

\section{Observação final}

Assim como os terreiros e as senzalas, as vendas eram lugares que guardavam espaço para práticas de consumo alcoólico, cuja natureza estava relacionada a formas de resistência que frequentemente incluíam atritos com as normas da religião e da cultura dominante. $\mathrm{Na}$ fazenda, os senhores estimulavam o consumo do álcool, mas, com relação às vendas, por outro lado, havia um esforço que atravessou todo o período da escravidão para se proibir a frequência dos escravizados e para se evitar o consumo do destilado. A ingestão de álcool na venda burlava a vontade senhorial de regulação da oferta da substância e permitia que os escravizados elaborassem suas próprias percepções da realidade dentro e fora das práticas religiosas. $\mathrm{O}$ acesso ao álcool era conquistado por meio do roubo de ouro, café, açúcar etc. $\mathrm{Na}$ venda, o escravo bebia o malungo com seu malungo pagando-o com seus próprios meios, o que transformava aquele local em instituição importante para seus frequentadores porque, dentre outras coisas, abrigava ritos de passagem com estados liminares constituintes de uma cultura etílica recriada a partir de um referencial oriundo da África Centro-Ocidental.

Se as vendas foram de fato palco dessas experiências de alcoolização como informam os autores mencionados no início deste texto, elas foram, portanto, espaços que contribuíram para o processo de reconstrução identitária e reinvenção de humanidade dos 
africanos e afro-brasileiros em cativeiro. Por terem sido frequentadas por uma variedade de categorias sociais que se encontravam para uma miríade de atividades e com oportunidade de diálogo, essa cultura etílica foi estofo para a constituição de um espaço público onde gente escravizada, trabalhadoras e trabalhadores pobres podiam se comunicar, trocar ideias e informações, pensar e construir outros mundos dentro do horizonte de expectativas permitido pela temporalidade em que viveram. O desdobramento da pesquisa permitirá investigar os componentes históricos dessa temporalidade e testar a validade das proposições elaboradas neste estudo.

\section{Referências}

ACOSTINI, Camilla. Africanos no cativeiro e a construção de identidades no além-mar: Vale do Paraíba, século XIX. Dissertação (Mestrado em História) - Instituto de Filosofia e Ciências Humanas da Universidade Estadual de Campinas. Campinas, 2002.

ACOSTINI, Camilla. As artes da Ngoma no Brasil: o jongo/caxambu e as comunidades escravas no sudeste oitocentista. Anais do I Seminário de Pós-Graduandos do CEO/PRONEX, Rio de Janeiro, 2007.

ALENCASTRO, Luiz Felipe de. 0 trato dos viventes. São Paulo: Companhia das Letras, 2000. ANDRADE, Mário de. O samba rural paulista. Revista do Arquivo Municipal de São Paulo, São Paulo, ano IV, v. XLI, nov. 1937.

BLUTEAU, Raphael. Vocabulario portuguez \& latino. V. 5 (Letras K-N). Lisboa: Officina de Pascoal da Sylva, Impressor de Sua Magestade, 1716. Disponível em: https://digital.bbm.usp.br/view/?45000008429\#page/1/mode/2up. Acesso em: 11 ago. 2020.

BLUTEAU, Raphael. Vocabulario portuguez \& latino. V. 8 (Letras T-Z). Lisboa: Officina de Pascoal da Sylva, Impressor de Sua Magestade, 1721. Disponível em: https://digital.bbm.usp.br/handle/bbm/5441. Acesso em 26 jul. 2020.

BLUTEAU, Raphael. Supplemento ao vocabulario portuguez e latino. Parte II. Lisboa: Patriarcal Officina da Musica, 1728. Disponível em: https://digital.bbm.usp.br/view/?45000008425\#page/1/mode/2up. Acesso em: 11 ago. 2020. 
BRASIL, Antonio Americano do. Cancioneiro de trovas do Brasil Central. São Paulo: Editora Monteiro Lobato, 1925.

BENCl, Jorge. Economia cristã dos Senhores no Governo dos Escravos. São Paulo: Crijalbo, 1977.

BEZERRA-PEREZ. Carolina dos Santos. Saravá jongueiro Velho! Memória e ancestralidade no Jongo de Tamandaré. Juiz de Fora: Editora UFF, 2012.

CASCUDO, Luís da Câmara. Made in Africa. São Paulo: Clobal, 2001 [1965].

CHAVES, Maria das Graças. Perfeitos negociantes: mercadores das minas setecentistas. São Paulo: Annablume, 1999.

COUTY, Louis. A escravidão no Brasil. Rio de Janeiro: Casa de Rui Barbosa, 1988.

DIAS, Paulo. A outra festa negra. In: JANCSÓ, István; KANTOR, Iris. Festa: cultura e sociabilidade na América Portuguesa. São Paulo: Hucitec/Edusp/Fapesp/Imprensa Oficial, 2001.

EBEL, Ernst. Rio de Janeiro e seus arredores. São Paulo: Companhia Editora Nacional, 1972.

FANON, Frantz. Racismo e cultura. Portal Geledés, 27 mai. 2014. Disponível em: https://www.geledes.org.br/racismo-e-cultura-leitura-psicanalitica-e-politica-defrantz-fanon. Acesso em: 26 jul. 2020.

FICUEIREDO, Luciano. $\mathbf{O}$ avesso da memória. Cotidiano e trabalho da mulher em Minas Gerais no século XVIII. Rio de Janeiro: José Olympio, 1993.

FLORENCE, Hercules de. Viagem fluvial do Tietê ao Amazonas pelas províncias brasileiras de São Paulo, Mato Grosso e Grão Pará (1825-1829). Brasília: Senado Federal, 2007.

GALLET, Luciano. Estudos de folclore. Rio de Janeiro: Editores Brasil, 1934.

HABERMAS, Jürgen. Mudança estrutural da esfera pública: investigação sobre uma categoria da sociedade burguesa. São Paulo: Editora Unesp, 2014.

KARASCH, Mary. A vida dos escravos no Rio de Janeiro (1808-1850). São Paulo: Companhia das Letras, 2000.

LAMAN, Karl. The Kongo (v. II). Estocolmo: Victor Pettersons Bokindustri Aktiebolag, 1953.

LOPES, Nei. Bantos, males e identidade negra. Rio de Janeiro: Forense Universitária, 1988.

MACHADO, Maria Helena Pereira Toledo. O plano e o pânico: movimentos sociais na década da Abolição. São Paulo: Edusp, 2010.

MAIOR, Mário Souto. Cachaça. Brasília: Thesaurus, 1985. 
MORAES SILVA, Antonio de. Diccionario da lingua portugueza. Lisboa: Typographia Lacerdina, 1813.

POEL, Francisco van der. Dicionário da religiosidade popular: cultura e religião no Brasil. Curitiba: Nossa Cultura, 2013.

POLLAK, Michael. Memória, esquecimento, silêncio. Estudos Históricos, Rio de Janeiro, v. 2, n. 3, p. 3-15, 1989.

RIBEYROLLES, Charles. Brasil pitoresco. São Paulo: Edusp, 1980.

RUBIM, Braz da Costa. Vocabulario brasileiro para servir de complemento aos diccionarios da língua portugueza. Rio de Janeiro: Typ. Dous de Dezembro de Paula Brito Impressor da Casa Imperial, 1853.

SILVA PINTO, Luiz Maria da. Diccionario da Lingua Brasileira. Ouro Preto: Typographia de Silva, 1832. Disponível em: <https://digital.bbm.usp.br/handle/bbm/5414>. Acesso em 26 jul. 2020.

SLENES, Robert. "Malungu, ngoma vem!": África coberta e descoberta do Brasil". Revista USP, São Paulo, n. 12, pp. 48-67, 1992.

SLENES, Robert. "Eu venho de muito longe, eu venho cavando": jongueiros cumba na senzala centro-africana. In: LARA, Silvia Hunold; PACHECO, Gustavo (orgs.). Memória do jongo: as gravações históricas de Stanley ]. Stein, Vassouras, 1949. Rio de Janeiro/Campinas: Folha Seca/Cecult, 2007, p. 109-156.

SLENES, Robert. A árvore de Nsanda transplantada: cultos kongo de aflição e identidade escrava no Sudeste brasileiro (século XIX). In: LIBBY, Douglas; FURTADO, Júnia Ferreira (orgs.). Trabalho livre, trabalho escravo: Brasil e Europa, séculos XVIII e XIX. São Paulo: Annablume, 2006, p. 273-316.

SMITH, Frederick H. Caribbean Rum: A Social and Economic History. Gainesville: University Press of Florida, 2005.

STEIN, Stanley ]. Vassouras: um município brasileiro do café, 1850-1900. Rio de Janeiro: Nova Fronteira, 1990.

THORNTON, ]. Africa and Africans in the Making of the Atlantic World, 1400-1680. Cambridge: Cambridge University Press, 2002.

WILLIAMS, Eric. Capitalismo e escravidão. São Paulo: Companhia das Letras, 2012.

WILSON, Thomas. Drinking cultures: Sites and Practices in the Production and Expression of Identity. Oxford: Berg, 2005. 